\title{
Self-cleaning surfaces as an innovative potential for sustainable concrete
}

\author{
M. Hunger \& H.J.H. Brouwers \\ Faculty of Engineering Technology, University of Twente, Enschede, The Netherlands
}

\begin{abstract}
Concrete technology is subject of continuous development and improvement. One of the very recent contributions to durability and sustainability of concrete is the self-cleaning ability. This effect is achieved by applying photocatalytic materials to the concrete mix. This paper describes the effect of self-cleaning and air purification. Since about 10 years concrete paving stones, provided with this function, are available. With the development of a test setup and using nitric oxide (NO) as model pollutant an approach was found to quantitatively assess the air-purifying ability of those paving stones. This seems to be of interest since a real comparative analysis of air purifying concrete products is not available and the establishment of a measurement standard for concrete products is still in a draft-state. A brief technical description of this test setup will be presented to the reader. Using this innovative setup, the influences on the degradation efficiency are studied and a basic reaction model is derived.
\end{abstract}

\section{INTRODUCTION}

Despite intensifying immission control requirements (e.g. EU (1999)) and the increased installation of emission reduction systems, the air pollution and in particular the exhaust gas pollution by nitrogen oxides (NO) will be a serious issue in the near future. The by far largest polluters are traffic and industrial flue gases. In this respect attempts regarding the active reduction of nitrogen oxides can be found in forms of filter devices for industrial stacks (denitrogenization DENOX plants) or active filter systems for e.g. tunnel exhausts. A further solution according to Matsuda et al. (2001) could be the photochemical conversion of (nitric oxides) $\mathrm{NO}_{\mathrm{x}}$ to nitric acid by semiconductor metal oxides due to heterogeneous photocatalytic oxidation (PCO).

In this respect titanium dioxide appears to be the most suitable semiconductor material. Titanium dioxide is one of the oxides of titanium, also called rutile titanium white. It appears in remarkable extent in nature (the ninth most abundant element in the earth's crust). In solid state titanium dioxide can appear in three different crystalline modifications namely rutile (tetragonal), anatase (tetragonal) and the seldom brookite (orthorhombic).

Two electrochemical properties turn the anatase modification to the best suitable catalyst. On the one hand the semiconductor band gap of, $E_{g}$, of $3.2 \mathrm{eV}$ is wide and on the other hand the potential for oxidization of the valence band is with $3.1 \mathrm{eV}($ at $\mathrm{pH}=0)$ relatively high. Both lead to the fact that almost any organic molecule can be oxidized in the presence of UV-light. This also applies for low oxidizable molecules. Besides the high efficiency anatase, in particular, is suitable for photocatalytic degradation because it is chemically stable, harmless and, compared to other semiconductor metal oxides relatively cheap.

When earlier work mainly dealt with the treatment of waste water, PCO recently has received considerable attention regarding the removal of pollutants in air. Since about 10 years efforts are made, first in Japan, in a large scale application of this photocatalytic reaction for air-purifying purposes. For the degradation of exhaust gases originated from traffic a sheet-like application close to the source would be desirable. Large illuminated surfaces in the road environment are for example road noise barriers and the road or sidewalk surfaces itself. Therefore noise barrier elements and paving stones are interesting substrates to study.

In construction industry products containing titanium dioxide are commercially available since the middle of the 1990s. These are for example window glass and ceramic tiles providing self-cleaning features. The production of the first concrete paving blocks containing titanium dioxide started in 1997 in Japan. The utilization of the self-cleaning abilities of titanium dioxide modified blends of cement was used for the first time in 1998 for the construction of the church "Dives in Misericordia" in Rome. In 2002, investigations to the application of a cement based asphalt slurry seal have been conducted in Italy.

The application of titanium dioxide in paving blocks is patent-protected for the European market by Murata 
et al. (1997) (Mitsubishi Materials Corporation) as well as Cassar et al. (2004) (Italcementi S.p.A.). The patent owned by Mitsubishi Materials Corporation comprises the application of titanium dioxide in a functional surface layer of a double-layer paving block having enhanced $\mathrm{NO}_{\mathrm{x}}$ cleaning capability. The patent held by Italcementi S.P.A. also covers the application of titanium dioxide in double-layer paving blocks capable of abating organic and inorganic pollutants. However, the patent furthermore claims the composition of a dry premix containing a hydraulic binder and a titanium dioxide based photocatalyst capable of oxidizing organic and inorganic pollutants present in the environment.

Besides the application of titanium dioxide for the degradation of organic and inorganic pollutants in paving blocks, noise barriers, and cementitious slurries for asphalt sealing, the material is used also because of its self-cleaning abilities. Here, preserving the original appearance of cementitious stone products is another motivation for the application of titanium dioxide in these products.

Regarding the current market situation, a wide variety of cement based products containing titanium dioxide can be found for horizontal and vertical application. Based on the patents owned by Mitsubishi Materials Corporation and Italcementi S.p.A., products with different properties are available on the European market. These products show varying amounts of titanium dioxide, having preferably the active anatase structure, but also the application of blends of titanium dioxide having anatase and rutile structure is comprised in the patents. These products are promoted regarding their photocatalytic capabilities under laboratory conditions. A comparative assessment in terms of the efficiency of different products as well as application techniques has not been carried out so far. The comparison of different products is rather difficult as different test procedures are used by the manufacturers. These test procedures differ in their execution and therefore a direct comparison of different products is questionable.

In Hüsken et al. (2007) a comparative study on the $\mathrm{NO}_{\mathrm{x}}$ degradation of active concrete surfaces is addressed. Thereby a representative profile of the economically available paving block products of the European market is considered. The presented paper is a continuation of this research using the results derived with one of these paving blocks as basis for further analysis. Furthermore the before developed test procedure and setup is applied and therefore briefly described in the following.

The reaction rate is an important parameter to evaluate and model the efficiency of PCO. For fluidized bed reactors and other types of photoreactors the PCO of $\mathrm{NO}_{\mathrm{x}}$ in presence of UV-light is well described in literature. However, for large scaled concrete applications there is no sufficient data available.

This paper addresses the development of a test setup capable of analyzing photocatalytic degradation of $\mathrm{NO}$ on concrete paving block samples. Using varying volumetric flow scenarios as well as different pollutant concentrations with otherwise constant test conditions a reaction model is derived describing the sample in terms of a reaction rate constant $(k)$ and an adsorption equilibrium constant $\left(K_{d}\right)$. Using these parameters, air-purifying concrete paving blocks can be explicitly described.

\section{THE MEASURING PRINCIPLE}

The photocatalytic efficiency of a system can be assessed by a number of criteria again being influenced by various circumstances and factors. Therefore a model pollutant was selected and a standard measurement procedure was defined as being explained in the following sections.

From the relevant literature it becomes clear that the degradation of nitric oxide (NO) or more general of nitrogen oxide $\left(\mathrm{NO}_{\mathrm{x}}\right)$, also referred to as DeNOxprocess (denitrogenization), delivers a suitable model to assess the ability of surfaces for air purification. This denitrogenization process can roughly be described as a two-stage reaction on the surface of a photocatalyst, which in most of the cases is titanium dioxide in the anatase modification or variants of it. For this purpose a certain amount of water molecules, supplied by the relative humidity, and electromagnetic radiation are required to start a degradation process. The electromagnetic radiation $(E)$ is expressed by the product of Planck's constant $(h)$ and the frequency $(v)$. Herewith, the two steps can be summarized as follows:

$\mathrm{NO}+\mathrm{OH}^{*} \stackrel{\text { hv }}{\longrightarrow} \mathrm{NO}_{2}+\mathrm{H}^{+}$

$\mathrm{NO}_{2}+\mathrm{OH}^{*} \stackrel{\text { hv }}{\longrightarrow} \mathrm{NO}_{3}^{-}+\mathrm{H}^{+}$.

The free hydroxyl radicals $(\mathrm{OH})$ originate from the photogenerated water electrolysis on the anatase surface. These two reactions describe the processes on the surface of the sample and therefore define the compounds which have to be measured in order to evaluate degradation ability. With the help of the deployed chemiluminescence $\mathrm{NO}_{\mathrm{x}}$ analyzer the amounts of $\mathrm{NO}_{\mathrm{x}}$ and $\mathrm{NO}$ can be quantified. Subsequently, the amount of $\mathrm{NO}_{2}$ can be calculated by difference formation. Hence, a quantitative analysis can be conducted.

The detection of nitrogen oxides is based on the reaction of nitric oxide with ozone $\left(\mathrm{O}_{3}\right)$. As a result of this reaction an excited nitrogen dioxide is produced. Due to the excited state luminescence, representing the 
excitation-energy, is emitted in the range from 560$1250 \mathrm{~nm}$. This chemiluminescence is measured by a photo diode with optical filters connected upstream. Ozone required for the oxidation is supplied by an ozone generator using dried ambient air. The percentage of $\mathrm{NO}_{2}$ contained in $\mathrm{NO}_{\mathrm{x}}$ will be reduced to $\mathrm{NO}$ in a converter before being conveyed to the measurement chamber. Here, solenoid-controlled valves will feed the measurement chamber in alternating sequence with the sample gas or reduced NO. Evaluation electronics will enable the constant measurement of $\mathrm{NO}_{\mathrm{x}}$ and NO this way.

\section{TEST APPARATUS}

As the pre-standard ISO TC 206/SC N (2004) serves as a sound basis for measurements, its recommendations were largely followed for the practical conduction of this experiment. In fact this standard holds for advanced technical fine ceramics but it satisfies the needs for measurements on concrete specimen as well.

The applied apparatus is composed of a reactor cell housing the sample, a suitable light source, a $\mathrm{NO}_{\mathrm{x}}$ analyzer, and an appropriate gas supply.

\subsection{Reactor}

The core of the experiment is a gas reactor allowing a planar sample of the size $100 \times 200 \mathrm{~mm}^{2}$ to be embedded. The schematic representation of the gas reactor is given in Figure 1.

Furthermore, the reactor is made from materials which are non-adsorbing to the applied gas and can withstand UV light of high radiation intensity. On top the reactor is tightly closed with a glass plate made from quartz or borosilicate, allowing the UV-radiation to pass through with almost no resistance. Within the reactor the planar surface of the test piece is fixed parallel to the covering glass, leaving an alterable slit height $h$ (most commonly $3 \mathrm{~mm}$ ) for the gas to pass through. The active sample area used for degradation was, deviating from the pre-standard, enlarged from $49.5 \mathrm{~mm} \pm 0.5 \mathrm{~mm}$ in width and $99.5 \mathrm{~mm} \pm 0.5 \mathrm{~mm}$ in length to $B=100 \mathrm{~mm}$ and $L=200 \mathrm{~mm}$ (with similar tolerance), which better complies with standard paving stone dimensions. By means of profiles and seals the sample gas only passes the reactor through the slit between sample surface in longitudinal direction and the glass cover. All structural parts inside the box are designed to enable laminar flow of the gas along the sample surface and to prevent turbulences.

\subsection{Light source}

The applied light source is composed of three fluorescent tubes of each $25 \mathrm{~W}$, emitting a high-concentrated UV-A radiation in the range of 300 to $400 \mathrm{~nm}$ with

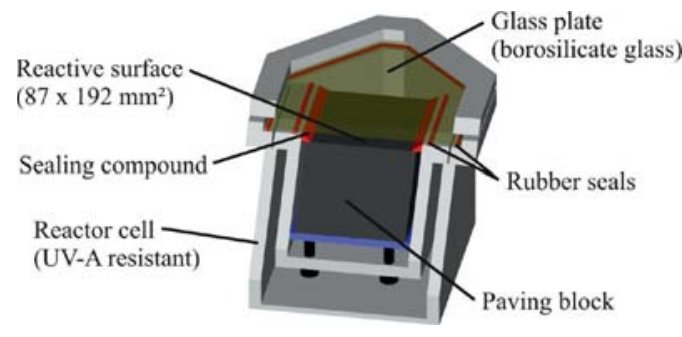

Figure 1. Schematic diagram of the gas reactor.

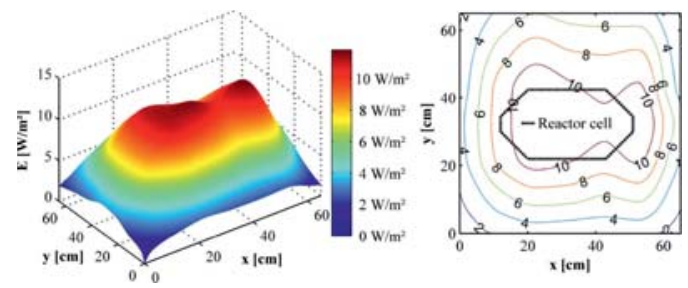

Figure 2. Distribution of UV-A irradiance within the test setup (left) and placement of the reactor box (right).

maximum intensity at about $345 \mathrm{~nm}$. Due to the narrow range in wavelength, an addition of a filter was not necessary. A warming of the reactor by the light source is not expected due to the spatial separation of light source and reactor, and a cooling of the lamp by means of fans. All fluorescent tubes can be adjusted in radiation intensity. With the help of a calibrated UVA radiometer the radiation intensity was adjusted to $10 \mathrm{~W} / \mathrm{m}^{2}$ at the sample surface. A lead time of about 15 minutes has to be considered for fluorescent tubes till a stable UV-A radiation is approached.

\subsection{Testing gas supply and gas types}

For the conduction of the experiment two different types of gas, filled in standard gas cylinders, are necessary. First, the model contaminant is discussed. For the pollution of the sample surfaces, nitric oxide (NO) is deployed. The used gas is composed of $50 \mathrm{ppmv}$ NO which is stabilized in nitrogen $\left(\mathrm{N}_{2}\right)$. As the concentration of gas, finally applied to the sample, will be adjusted to $1 \mathrm{ppmv}$, only small quantities of this gas are required. As transport fluid synthetic air, being composed of $20.5 \mathrm{vol} .-\%$ of oxygen $\left(\mathrm{O}_{2}\right)$ and $79.5 \mathrm{vol} .-\%$ of nitrogen, is deployed.

Since the gas cylinders are under high pressure, the gas needs to pass a pressure reducing valve before entering the system. Here pressure is first reduced to 0.3 bar. Before the two gas flows are merged, the model contaminant has to pass a high precision valve in order to adjust a pollution of $1 \mathrm{ppmv} \mathrm{NO}$ to the sample. The NO concentration can be monitored with 
the NO analyzer, connected to the outlet of the reactor box. Furthermore, the synthetic air will be conveyed through a gas-washing bottle, filled with demineralized water, in order to keep the relative humidity of the supplied gas constant at $50 \%$. Using a split gas flow, with one line passing a valve before the gas-washing bottle, one can realize desired humidity. Behind these two stages both gas flows, polluted and transport fluid, are mixed. With the help of a flow controller a volume flow of $Q=3 \mathrm{l} / \mathrm{min}$ is adjusted. The Reynolds number of the flow reads:

$\operatorname{Re}=\frac{\mathrm{v}_{\text {air }} \mathrm{D}_{\mathrm{h}} \rho_{\text {air }}}{\eta_{\text {air }}}=\frac{2 \mathrm{v}_{\text {air }} \mathrm{h} \rho_{\text {air }}}{\eta_{\text {air }}}=\frac{2 \mathrm{Q}}{\mathrm{Bv}_{\text {air }}}$.

$D_{h}$ is the hydraulic diameter of the considered channel, defined as four time the cross-sectional area divided by the perimeter, for the slit considered here, $D_{h}=2 \mathrm{~h}$. Substituting $Q=3 \mathrm{l} / \mathrm{min}, B=100 \mathrm{~mm}$ and $v_{\text {air }}=1.5410^{-5} \mathrm{~m}^{2} / \mathrm{s}\left(1\right.$ bar, $\left.20^{\circ} \mathrm{C}\right)$ yields $R e \approx 65$. Considering $h=3 \mathrm{~mm}$, the mean air velocity $v_{\text {air }}$ is $0.17 \mathrm{~m} / \mathrm{s}$ along the sample surface.

This low Reynolds number implies that the flow is laminar. A fully developed parabolic velocity profile will be developed at $L_{d}=0.05 \operatorname{Re} 2 \mathrm{~h}$, so here $L_{d} \approx 20 \mathrm{~mm}$, i.e. only at the first $10 \%$ of the slit length there are entrance effects, during the remaining $90 \%$ there is a fully developed laminar flow profile.

The gas, mixed and humidified this way, enters the reactor and is conveyed along the illuminated sample surface. At the opposite site of the reactor the gas leaves the chamber and is transported to a flue or outside with the help of an exhaust air duct. The NO analyzer sources the reacted test gas from this exhaust line. An adequate dimensioning of the hose line and, possibly, the installation of non-return valves prevents from suction of leak air from outside via the hose line to the analyzer.

\subsection{Analyzer}

For the gas analysis a chemiluminescent $\mathrm{NO}_{\mathrm{x}}$ analyzer like described in ISO 7996 was deployed. The analyzer is measuring the $\mathrm{NO}_{\mathrm{x}}$ and $\mathrm{NO}$ concentration in steps of $5 \mathrm{sec}$ while the corresponding $\mathrm{NO}_{\mathrm{x}}$ concentration is computed by the difference of the previous two. During the measurement the analyzer is constantly sampling gas with a rate of $0.81 / \mathrm{min}$. The detection limit of the deployed analyzer is at about $0.5 \mathrm{ppbv}$.

\section{EXPERIMENTS}

\subsection{The conduction of measurements}

For the development of a reaction model and the herewith related experiments only one sample was used. This way differences in measurement results due to varying surface roughness or unequal distribution of catalyst can be neglected. The deployed sample is a commercially available concrete paving stone whose photocatalytic properties were tested beforehand (Hüsken et al. (2007)). In preparation of each measurement the sample surface is cleaned in order to remove fouling, contamination and potential reaction products due to a previous $\mathrm{NO}_{\mathrm{x}}$ degradation. The cleaning process is always executed following a specified scheme using demineralized water. Subsequently, the sample is dried in a drying oven. For the measurement the sample with the reactive surface upwards is placed in the reaction chamber. With the help of an elastic sealing compound all gaps and joints around the sample are caulked that way, that the fed air could only pass the reactor along the reactive sample surface. In doing so a metal sheet of the dimension $87 \times 192 \mathrm{~mm}^{2}$ was deployed as a template for the sealing. The active sample surface was kept exactly identical for all measurements this way.

After assembling the sample the reactor is closed and the gas supply is started. The UV-A source is switched on as well in order to start the radiation stabilization, but the reactor stays covered to prevent first degradation. With the help of the controls the flow is now adjusted to e.g. $31 / \mathrm{m}$ and the relative humidity to $50 \%$. The supplied NO concentration is adjusted to the desired inlet concentration, which is checked by the analyzer. When these conditions appear to be stable the data acquisition is started. Now, for the first 5 minutes the system remained unchanged in order to flush the reactor chamber and to finally eliminate an increase of UV-A radiation. During this time the measured NO outlet concentration of the reactor was first decreasing and then approaching again the original inlet concentration. This phenomenon describes the saturation of surface with $\mathrm{NO}$ and was found to be a function of flow velocity, inlet concentration and surface character of the sample. After this period of time the cover sheet was removed to allow the radiation passing through the glass. This was very quickly responded by the analyzer. The degradation for the uncovered reactor lasted for 30 minutes, then the reactor was covered again and the data acquisition was continued for further 5 minutes. Within the last minutes of measurement the $\mathrm{NO}$ and $\mathrm{NO}_{\mathrm{x}}$ concentrations should ideally return to the original scale. As the reactor can be bridged, i.e. the pollutant can be directly transferred to the analyzer without passing the reaction camber, the NO inlet concentration at the end of a measurement was always compared with the original concentration at the beginning of the measurement. In this way measurement errors due to creeping $\mathrm{NO}$ concentrations during the measurement are prevented.

In order to obtain sufficient data for the development of a reaction model varying $\mathrm{NO}$ inlet concentrations of $0.1,0.3,0.5$, and $1.0 \mathrm{ppmv}$ were applied. 


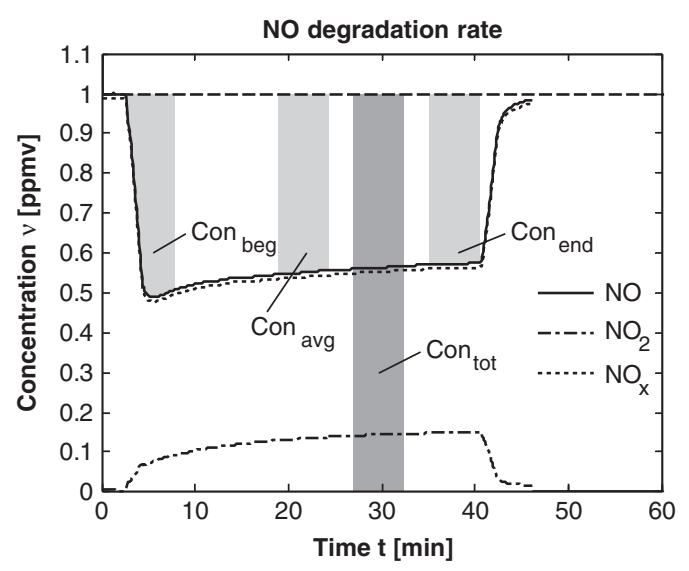

Figure 3. Explanation of the analysis approach for the description of the course of conversion.

Furthermore, for each inlet concentration the flow rate was varied by using flows of 1,3 and $51 / \mathrm{min}$. These different volumetric flows correspond to flow velocities of $0.056,0.167$ and $0.278 \mathrm{~m} / \mathrm{s}$ at the sample surface inside the reactor box. With these combinations a total number of 12 measurements are executed.

Moreover, to validate the assumption that conversion process is the limiting rate instead of the diffusion step, six more measurements with the above given flow rates but a fixed NO inlet concentration of $0.3 \mathrm{ppmv}$ have been done. In doing so the slit height in the reactor box was varied $(2,3$ and $4 \mathrm{~mm})$ for each flow rate. Note that stable and measurable NO inlet concentration was not achieved while applying a flow of $51 / \mathrm{min}$ and using a slit height of only $2 \mathrm{~mm}$. In that case the resistance of the system turned out to be too high and therefore a reliable measurement was not possible.

\subsection{Analysis of the data}

The data which is basis for the present analysis was derived applying above explained measurement procedure. Further analysis of the measurement data was conducted following a three stage analysis. For this purpose the course of the three different conversions $\left(\mathrm{NO}, \mathrm{NO}_{\mathrm{x}}\right.$ and $\mathrm{NO}_{2}$ ) was assessed for a time range of each five minutes equally distributed in the total measurement period. Figure 3 is illustrating this procedure for the formation of $\mathrm{NO}_{2}$ with an arbitrary sample. The degradation rate [\%] in the assessed time range is calculated by means of the ratio between actual conversion and the total conversion of $\mathrm{NO}\left(\mathrm{Con}_{t o t}\right)$ as follows:

Deg $_{\text {beg }}=\frac{\text { Con }_{\text {beg }}}{\text { Con }_{\text {tot }}}=1-\frac{C_{\text {out }}}{C_{\text {in }}}$.
The actual conversion for each five-minutes-period used in Equation 4 was determined by integration of the associated, descriptive function in the limits of time by using the trapezoid rule:

$$
\begin{aligned}
& \operatorname{Con}_{\text {beg }}=\sum_{\mathrm{i}=1}^{\mathrm{n}} \frac{\mathrm{t}_{\mathrm{i}+1}-\mathrm{t}_{\mathrm{i}}}{2}\left(\mathrm{v}_{\mathrm{i}}+\mathrm{v}_{\mathrm{i}+1}\right) \\
& \forall \mathrm{t}_{\mathrm{i}} \in\left[\mathrm{t}_{\text {beg }}, \mathrm{t}_{\text {beg }}+5 \mathrm{~min}\right] .
\end{aligned}
$$

This approach can be assumed to be sufficiently precise, given that the interval $\left[t_{i}, t_{i+1}\right]$ only lasts for $5 \mathrm{sec}$. Here, the first time interval for the beginning conversion $\left(\mathrm{Con}_{\mathrm{beg}}\right)$ starts at zero, when the sample in the reactor was first exposed to UV-A radiation and lasted for five minutes. This way the slope of the starting conversion up to the maximum degradation rate is included and therefore characterizing this first numerical value. In other words, the progress of the degradation development up to maximum conversion is included and evaluated. The second time frame $\left(C o n_{\text {avg }}\right)$ represents the conversion after half of the total time of UV-A exposition, i.e. the chronological middle of measurement \pm 2.5 minutes. For the last time interval $\left(\mathrm{Con}_{\text {end }}\right)$, the last five minutes before switching off the UV-A source are considered. The delayed decrease of conversion after the obvious inflection point is explained by the inertia of the whole system. As a matter of principle, no conversion can take place after removing the UV-A source. Already formed hydroxyl radicals still can start an oxidation of $\mathrm{NO}_{x}$ but only till they are consumed. For this reason the terminal degradation of $\mathrm{NO}_{\mathrm{x}}$ without UV-A exposition is not further assessed. The conversion of the last 5-minutes-range is taken as basis for the further analysis.

\section{REACTION MODEL}

\subsection{Model development}

In this section the reaction process in the reactor is modeled. First, one should observe that the NO had to diffuse to the concrete surface, where subsequently the conversion to $\mathrm{NO}_{\mathrm{x}}$ takes place. So the process contains two transfer steps, the mass transfer from gas to wall and the conversion at the concrete surface. In line with findings by Zhao and Yang (2003) and Dong et al. (2007), here it will be demonstrated that the conversion is the rate limiting step.

The NO mass flux from gas to surface is governed by:

$\dot{\mathrm{m}}=\frac{\mathrm{ShD}}{\mathrm{D}_{\mathrm{h}}}\left(\mathrm{C}_{\mathrm{g}}-\mathrm{C}_{\mathrm{w}}\right)=\frac{\mathrm{ShD}}{2 \mathrm{~h}}\left(\mathrm{C}_{\mathrm{g}}-\mathrm{C}_{\mathrm{w}}\right)$,

with $D_{h}$, as hydraulic diameter, see Section 3.3 and $C_{g}$ and $C_{w}$ are the $\mathrm{NO}$ concentrations (in $\mathrm{mg} \mathrm{NO}$ per $\mathrm{m}^{3}$ 
air) in air (mean mixed or bulk) and on the surface. The relation between $C$ and $C_{c o n}$ is as follows:

$\mathrm{C}=\frac{\mathrm{M}_{\mathrm{NO}} \rho_{\text {air }}}{\mathrm{M}_{\text {air }}} \mathrm{C}_{\text {con }}$,

Considering that the molecular mass of air $\left(M_{\text {air }}\right)$ is $29 \mathrm{~g} / \mathrm{mole}\left(80 \% M_{N 2}\right.$ and $\left.20 \% M_{O 2}\right)$, that of $\mathrm{NO}\left(M_{N O}\right)$ is $30 \mathrm{~g} / \mathrm{mole}$, and that $\rho_{\text {air }}$ is about $1 \mathrm{~kg} / \mathrm{m}^{3}$, it follows that $C_{g}$ (in $\left.\mathrm{kg} / \mathrm{m}^{3}\right)$ is about $C_{\text {con }}$ (in mole/mole), or equivalently, $C_{g}$ (in $\mathrm{mg} / \mathrm{m}^{3}$ ) is about $C_{c o n}$ (in ppmv $=10^{-6}$ mole $/$ mole).

$S h$ is the Sherwood number, amounting to about 5 for slits with one inert and one exchanging side (Shah and London (1974)), and $D$ the diffusion coefficient of NO in air, which amounts to about $1.510^{-5} \mathrm{~m}^{2} / \mathrm{s}$ $\left(\sim v_{\text {air }}\right)$.

If it is assumed that the diffusion to the concrete surface is the limiting step (conversion takes place instantaneously and completely), the NO concentration at the surface will be zero. The NO mass balance equation then reads:

$v_{\text {air }} h \frac{d_{g}}{d x}=-m=-\frac{S h D B}{2 h} C_{g}$,

with as boundary condition:

$\mathrm{C}_{\mathrm{g}}=\mathrm{C}_{\mathrm{g}, \text { in }}$.

Integrating Equation 8 and application of Equation 9 yields:

$$
\frac{C_{g, \text { out }}}{C_{g, \text { in }}}=e^{-\frac{S h D L}{2 v_{\text {air }} h^{2}}},
$$

with $C_{g, \text { out }}=C_{g}(x=L), L$ being the length $(200 \mathrm{~mm})$. Substituting all variables, including $v_{\text {air }}=0.17 \mathrm{~m} / \mathrm{s}$ and $h=3 \mathrm{~mm}$ (Section 3.3), into Equation 10 yields $C_{g, \text { out }} / C_{g, \text { in }} \approx 0.04$. In other words, in the case that the diffusion to the wall would be rate limiting step, the exit concentration would be close $4 \%$ of the inlet concentration, i.e. $96 \%$ of the NO would be converted. The present measurements and previous research (Hüsken et al. (2007)) learned this is not the case, so that the conversion rate at the surface cannot be ignored (cp. Tables 1 and 2). In the following, it is now assumed a priori that the conversion is the rate limiting step, so that $\mathrm{C}_{\mathrm{w}}$ now equals $\mathrm{C}_{\mathrm{g}}$, which will be verified $a$ posteriori.

For the prevailing photocatalytic gas-solid surface reaction, only adsorbed NO can be oxidized. In the past therefore the Langmuir-Hinshelwood rate model has been widely used, e.g. by Ollis (1993), Dong et al.
Table 1. NO outlet concentrations of the reactor considering varying inlet concentrations and flow rates for the photocatalysis of the paving stone example.

\begin{tabular}{|c|c|c|c|c|c|c|}
\hline \multirow{3}{*}{$\begin{array}{l}\mathrm{C}_{\text {in }} \\
\text { [ppmv] }\end{array}$} & \multirow{2}{*}{\multicolumn{3}{|c|}{$\begin{array}{l}\mathrm{C}_{\text {out }} \\
\text { Volumetric flow rate } \\
\text { Q [1/min }]\end{array}$}} & \multirow{2}{*}{\multicolumn{3}{|c|}{$\begin{array}{l}\mathrm{NO}_{\mathrm{x}} \text { removal rate }[\%] \\
\text { Volumetric flow rate } \\
\mathrm{Q}[1 / \mathrm{min}]\end{array}$}} \\
\hline & & & & & & \\
\hline & 1 & 3 & 5 & 1 & 3 & 5 \\
\hline 0.1 & 0.011 & 0.032 & 0.041 & 89.0 & 68.4 & 59.4 \\
\hline 0.3 & 0.039 & 0.157 & 0.197 & 87.1 & 47.6 & 34.3 \\
\hline 0.5 & 0.210 & 0.309 & 0.356 & 58.0 & 38.3 & 28.9 \\
\hline 1.0 & 0.334 & 0.729 & 0.779 & 66.6 & 27.1 & 22.1 \\
\hline
\end{tabular}

Table 2. NO outlet concentrations and removal rates of the reactor considering constant inlet concentration $\mathrm{C}_{\text {in }}=0.3$ ppmv but varying flow rates and slit heights.

\begin{tabular}{|c|c|c|c|c|c|c|}
\hline \multirow{3}{*}{$\begin{array}{l}\text { Slit } \\
\text { height }\end{array}$} & \multicolumn{3}{|l|}{$\mathrm{C}_{\text {out }}$} & \multicolumn{3}{|c|}{$\mathrm{NO}_{\mathrm{x}}$ removal rate $[\%]$} \\
\hline & \multicolumn{3}{|c|}{$\begin{array}{l}\text { Volumetric flow } \\
\text { rate } Q[1 / \mathrm{min}]\end{array}$} & \multicolumn{3}{|c|}{$\begin{array}{l}\text { Volumetric flow } \\
\text { rate } Q[1 / \mathrm{min}]\end{array}$} \\
\hline & 1 & 3 & 5 & 1 & 3 & 5 \\
\hline 2 & 0.093 & 0.162 & - & 68.8 & 46.1 & - \\
\hline 3 & 0.039 & 0.157 & 0.197 & 87.1 & 47.6 & 34.3 \\
\hline 4 & 0.065 & 0.157 & 0.183 & 78.3 & 47.6 & 39.1 \\
\hline
\end{tabular}

(2007), see also Zhao and Yang (2003), and which will also be applied here. Following this model, the disappearance rate of reactant reads:

$\mathrm{r}=\frac{\mathrm{kK}_{\mathrm{d}} \mathrm{C}_{\mathrm{g}}}{1+\mathrm{K}_{\mathrm{d}} \mathrm{C}_{\mathrm{g}}}$,

with $k$ as reaction rate constant $\left(\mathrm{kg} / \mathrm{m}^{3} \mathrm{~s}\right)$ and $K_{d}$ as the adsorption equilibrium constant $\left(\mathrm{m}^{3} / \mathrm{kg}\right)$. The $\mathrm{NO}$ balance equation now reads:

$v_{\text {air }} \frac{\mathrm{dC}_{\mathrm{g}}}{\mathrm{dx}}=-\mathrm{r}=-\frac{\mathrm{kK}_{\mathrm{d}} \mathrm{C}_{\mathrm{g}} \mathrm{B}}{1+\mathrm{K}_{\mathrm{d}} \mathrm{C}_{\mathrm{g}}}$.

Integration and using boundary condition 9 yields:

$\frac{1}{\mathrm{k}}+\frac{1}{\mathrm{kK}_{\mathrm{d}}} \frac{\mathrm{Ln}\left(\frac{\mathrm{C}_{\mathrm{g}, \text { in }}}{\mathrm{C}_{\mathrm{g}, \text { out }}}\right)}{\left(\mathrm{C}_{\mathrm{g}, \text { in }}-\mathrm{C}_{\mathrm{g}, \text { out }}\right)}=\frac{\mathrm{L}}{\mathrm{v}_{\text {air }}\left(\mathrm{C}_{\mathrm{g}, \text { in }}-\mathrm{C}_{\mathrm{g}, \text { out }}\right)}=$

$\frac{\mathrm{V}_{\text {reactor }}}{\mathrm{Q}\left(\mathrm{C}_{\mathrm{g}, \text { in }}-\mathrm{C}_{\mathrm{g}, \text { out }}\right)}$. 


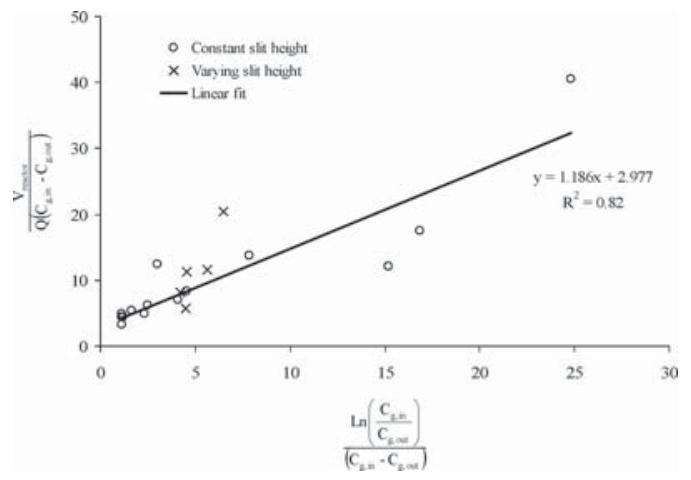

Figure 4. Regression results of data presented in Table 1 and Table 2 for the photocatalysis of the paving stone example.

As $V_{\text {reactor }}=L B h$ and $Q=v_{\text {air }} B h$, again, $C_{g, \text { out }}=C_{g}$ $(x=L)$.

In Table 1 this $C_{g, \text { out }}$ of the experiments with the paving stone is summarized, the inlet concentration $C_{g, \text { in }}$ had values of $0.1,0.3,0.5$ and $1 \mathrm{mg} / \mathrm{m}^{3}$ (or ppmv), and the flow rate $Q$ was 1,3 and $51 / \mathrm{min}$.

\subsection{Validation of the model}

In Figure 4, $y=V_{\text {reactor }} / Q\left(C_{g, \text { in }}-C_{g, \text { out }}\right)$ is set out ver$\operatorname{sus} x=\operatorname{Ln}\left(C_{g, \text { in }} / C_{g, \text { out }}\right) /\left(C_{g, \text { in }}-C_{g, \text { out }}\right)$, and the data fit with the line $y=(1.19 \mathrm{~s}) x+2.98 \mathrm{~m}^{3} \mathrm{~s} / \mathrm{mg}$. The intersection with the ordinate corresponds to $1 / k$, so that $k=0.37 \mathrm{mg} / \mathrm{m}^{3} \mathrm{~s}$, and the slope to $1 / k K_{d}$, so that $K_{d}=2.51 \mathrm{~m}^{3} / \mathrm{mg}$.

Wang et al. (2007) obtained $k=6.84 \mathrm{mg} / \mathrm{m}^{3} \mathrm{~s}$ and $K_{d}=1.13 \mathrm{~m}^{3} / \mathrm{mg}$ for the NO degradation by woven glass fabrics, their inlet NO concentration being in the range 40 to 80 ppmv. Concerning the photo catalytic ammonia degradation by cotton woven fabrics, Dong et al. (2007) obtained $k=0.10 \mathrm{mg} / \mathrm{m}^{3} \mathrm{~s}$ and $0.24 \mathrm{mg} / \mathrm{m}^{3} \mathrm{~s}$, and $K_{d}=0.035 \mathrm{~m}^{3} / \mathrm{mg}$ and $0.112 \mathrm{~m}^{3} / \mathrm{mg}$, whereby the $\mathrm{NH}_{3}$ inlet concentration ranged from 14 to $64 \mathrm{mg} / \mathrm{m}^{3}$.

With the obtained values of $k$ and $K_{d}$ the conversion rate and diffusion rate can be compared. Dividing the conversion/transfer rates as governed by Equations 12 and 8 yields $k K_{d} 2 h^{2} / S h D$, and substituting the prevailing values learns that this ratio is about 0.2 , i.e. the diffusion rate is about five times the conversion rate. Note that the employed $k K_{d}$ is an upper limit for $k K_{d} /\left(1+K_{d} C_{g}\right)$, so that the actual ratio will even be smaller. From this small conversion/transfer rate ratio one can conclude that indeed the degradation rate is much slower than the diffusion rate, and hence it is the limiting rate. This is also confirmed by Matsuda et al. (2001) who found conversion rates proportionally increasing with the specific surface area of the applied titanium dioxide.
Table 3. NO removal and $\mathrm{NO}_{\mathrm{x}}$ removal rate for a concrete paving block taken from literature (Mitsubishi (2005)).

\begin{tabular}{lll}
\hline $\begin{array}{l}\text { NO concentration } \\
{[\mathrm{ppm}]}\end{array}$ & $\begin{array}{l}\text { NO removal } \\
{\left[\mathrm{mmol} / \mathrm{m}^{2} 12 \mathrm{~h}\right]}\end{array}$ & $\begin{array}{l}\mathrm{NO}_{\mathrm{x}} \text { removal rate } \\
{[\%]}\end{array}$ \\
\hline 0.05 & 0.2 & 89.6 \\
0.1 & 0.4 & 88.9 \\
0.2 & 0.8 & 90.6 \\
0.5 & 2.0 & 88.4 \\
1.0 & 3.7 & 82.3 \\
2.0 & 6.1 & 68.0 \\
5.0 & 10.0 & 44.3 \\
\hline
\end{tabular}

In the addressed research this fact was furthermore investigated by executing experiments with slit heights of 2 and $4 \mathrm{~mm}, C_{g, \text { in }}$ taken as $0.3 \mathrm{mg} / \mathrm{m}^{3}$ $(0.3 \mathrm{ppmv})$, and the flow rate $Q$ was 1,3 and $51 / \mathrm{min}$. In Table 2, and also in Figure 4, these data are included. With except for the smallest flow rate, the degradation rates match well with the values listed in Table 1 , and the computed $V_{\text {reactor }} / Q\left(C_{g, \text { in }}-C_{g, \text { out }}\right)$ and $\operatorname{Ln}\left(C_{g, \text { in }} / C_{g, \text { out }}\right) /\left(C_{g, \text { in }}-C_{g, \text { out }}\right)$ are also compatible with the previous ones set out in Figure 4 and the fitted trend line.

The above literature review shows that the Langmuir-Hinshelwood model has been frequently applied to characterize photocatalytic gas-solid surface processes using various substrate materials. However, to the authors' knowledge, the kinetics of photocatalytic acting concrete has not been analyzed so far.

Other relevant data on photocatalysis on concrete was found in Mitsubishi (2005). Here, amongst other things, data is presented on the $\mathrm{NO}_{\mathrm{x}}$ removal of a paving stone type (NOXER) which is exposed to varying NO concentrations. With the help of background information regarding the setup and conduction of measurement an analysis according to the Langmuir-Hinshelwood model was derived. The information given on the flow properties were sufficient for adequate application of the model.

Using the data on the $\mathrm{NO}_{\mathrm{x}}$ removal rate given in Table 3 a linear fit is derived as given in Figure 5. As can be seen the resulting data points fit remarkably well into the proposed model.

With the obtained values again a conversion rate and diffusion rate can derived. For the given data $k$ amounts to $3.54 \mathrm{mg} / \mathrm{m}^{3} \mathrm{~s}$ and $K_{d}$ to $0.538 \mathrm{~m}^{3} / \mathrm{mg}$, respectively. Compared to the own experiments the conversion rate is notedly higher than the transfer rate in this case. On the conversion side this can be explained with different amounts and types of catalyst (anatase) whereas the transfer could be influenced by different surface morphology of the paving stones. The ratio of conversion/transfer rates therefore amounts to 0.45 for the 


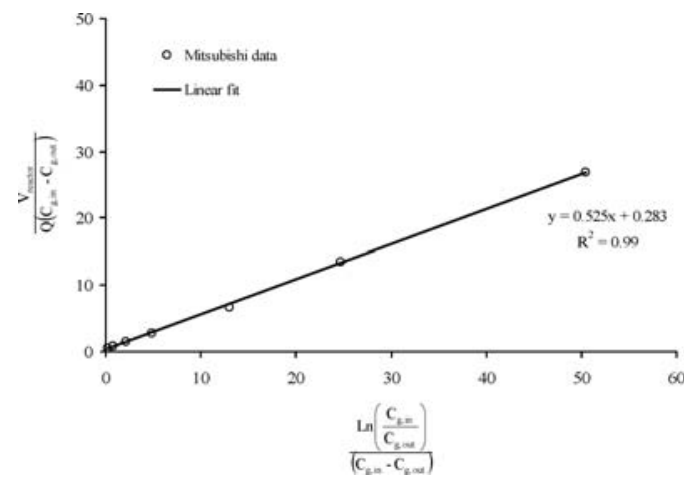

Figure 5. Regression results of data presented in Table 3 for the photocatalysis of a NOXER paving block (data taken from Mitsubishi (2005)).

NOXER case, i.e. the conversion rate is still more than twice the diffusion rate.

\section{CONCLUSION}

Heterogeneous photocatalytic oxidation is a promising air-purifying technology. Besides this, the selfcleaning aspect coming along with PCO should not be ignored either. Concerning this matter also promising results have been achieved. They are described elsewhere as it is out of the scope of this paper.

The results obtained on the air-purification show that a successful decomposition of $\mathrm{NO}_{\mathrm{x}}$ along concrete paving stone surfaces is feasible by using PCO in the presence of UV light. For the assessment of those active paving stones a setup has been developed which is capable of varying and controlling all boundary conditions like for example the volumetric air flow, slit height, NO inlet concentration, UV-irradiance and relative humidity.

Besides the development of the setup a test procedure has been suggested as well. Following this procedure, first time a standard could be obtained which would allow for the real quantitative comparison of concrete paving blocks capable of degrading $\mathrm{NO}_{\mathrm{x}}$ from the air

For this research both experimental and modeling work has been conducted. With the derivation of a reaction model, based on Langmuir-Hinshelwood kinetics, now the treatment performance of certain air-purifying concrete products for decomposition of gaseous pollutants (NO) can be predicted. Furthermore, now the unique description of a photocatalytic material is feasible by the derivation of its conversion and adsorption rate constants. The derived model also confirms that the conversion of $\mathrm{NO}_{\mathrm{x}}$ is the rate-determining step in the photocatalytic oxidation of $\mathrm{NO}_{\mathrm{x}}$.

\section{ACKNOWLEDGMENT}

The authors gratefully acknowledge the assistance of Dipl.-Ing. G. Hüsken with helping with the conduction and analysis of measurements. Moreover, the authors wish to express their sincere thanks to the European Commission (I-Stone Project, Proposal No. 515762-2) and the following sponsors of the research group: Bouwdienst Rijkswaterstaat, Rokramix, Betoncentrale Twenthe, Betonmortelcentrale Flevoland, Graniet-Import Benelux, Kijlstra Beton, Struyk Verwo Groep, Hülskens, Insulinde, Dusseldorp Groep, Eerland Recycling, Enci, Provincie Overijssel, Rijkswaterstaat Directie Zeeland, A\&G Maasvlakte (chronological order of joining).

\section{REFERENCES}

Dong, Y., Bai, Z., Liu, R., Zhu, T. 2007. Decomposition of indoor ammonia with $\mathrm{TiO} 2$-loaded cotton woven fabrics prepared by different textile finishing methods. Atmospheric Environment 41(15): 3182-3192.

EU - The Council of the European Union. 1999. Council Directive 1999/30/EC - relating to limit values for sulphur dioxide, nitrogen dioxide and oxides of nitrogen, particulate matter and lead in ambient air.

Hüsken, G., Hunger, M., Brouwers, H.J.H. 2007. Comparative study on cementitious products containing titanium dioxide as photo-catalyst, Proceedings International RILEM Symposium on Photocatalysis, Environment and Construction Materials-TDP 2007, 8-9 October 2007, Florence, Italy, 147-154, Eds. P. Baglioni and L. Cassar, RILEM Publications, Bagneux, France (2007).

Matsuda, S., Hatano, H., Tsutsumi, A. 2001. Ultrafine particle fluidization and its application to photocatalytic NOx treatment. Chemical Engineering Journal 82(1-3): $183-188$.

Mitsubishi Materials Corporation 2005. NOx removing paving block utilizing photocatalytic reaction. In brochure Noxer - NOx removing paving block.

Ollis, D.F. 1993. Photoreactors for Purification and Decontamination of air. In D. F. Ollis and H. Al-Ekabi (eds.), Photocatalytic purification and treatment of water and air. Elsevier Science: 481-494.

Shah, R.K., \& London A.L. 1974. Thermal BoundaryConditions and Some Solutions for Laminar Duct Flow Forced Convection, Journal of Heat Transfer 96(2): $159-165$.

Wang, H.Q., Wu, Z.B., Zhao, W.R., Guan, B.H. 2007. Photocatalytic oxidation of nitrogen oxides using $\mathrm{TiO} 2$ loading on woven glass fabric. Chemosphere 66(1): 185-190

Zhao, J. \& Yang, X.D. 2003. Photocatalytic oxidation for indoor air purification: a literature review. Building and Environment 38(5): 645-654. 